\title{
Liberalismo, participación política y pertenencia cultural
}

\author{
MARIANO C. MELERO DE LA TORRE \\ UNED, Madrid
}

\begin{abstract}
Asistimos en nuestras democracias actuales a una situación paradójica. La apatía de los ciudadanos de las sociedades mayoritarias, orientados casi exclusivamente en función de sus intereses profesionales y familiares, contrasta con la persistente lucha política de los grupos nacionales minoritarios por lograr su reconocimiento. De forma casi imperceptible, el lamento por la escasa implicación de los ciudadanos en el bien común se transforma generalmente en temor cuando de lo que se trata es de otorgar derechos políticos a aquellos subgrupos del país que se sienten y se proclaman sociedades separadas. En este breve artículo intentaré aclarar la naturaleza de la participación política, cuáles son sus fuentes y hasta qué punto está justificado el temor a reconocer de manera universal el autogobierno de los «pueblos». Para ello, analizaré dos modelos de participación política: el modelo comunitarista de Charles Taylor y el modelo democrático de Jürgen Habermas.
\end{abstract}

¿Qué debemos entender por participación política? En términos generales, la concepción que usemos de participación dependerá del tipo de comunidad, o del aspecto de la comunidad, en el que decidamos considerar la integración o socialización de un individuo. Si hablamos de la comunidad política, la participación consiste en «la pertenencia a un Estado», lo cual implica, en las sociedades liberales democráticas, la posesión de un status de derechos y deberes que garantiza a los individuos un ámbito de libertad de acción en el que, dentro de los límites impuestos por la ley, no pueden verse constreñidos o coaccionados por ninguna autoridad ajena a su voluntad ${ }^{1}$.

Los críticos de esta noción meramente negativa de la libertad insisten en que no vale de nada una declaración formal de derechos y deberes si luego no se dan las condiciones necesarias para su realización. La libertad individual, dicen, sólo puede ser ejercida en un tipo de sociedad. Los individuos no son átomos aislados. Sus identidades, así como el curso de sus acciones, dependen del trasfondo social y cultural. El ciudadano moderno, con su status de derechos bien protegido, es el producto de un determinado tipo de civilización $-\mathrm{O}$ de una forma específica de asociación política caracterizada por el imperio de la ley, las reglas de igual respeto, los hábitos de deliberación y asociación, etc.- cuya supervivencia no está nunca definitivamente garantizada. Por este motivo, los individuos libres deben participar activamente en el sostenimiento de ese contexto social que les permite ejercer la libertad. La participación política, en este sentido, significa la obligación de servir a la comunidad, lo que exige no sólo derechos (y deberes) de no-interferencia, sino también deberes de solidaridad, fraternidad y mutuo entendimiento, así como un sentimiento compartido de lealtad hacia las instituciones comunes.

Los defensores de este tipo de participación suelen ser críticos con el liberalismo. Piensan que la defensa liberal de los derechos individuales es incapaz de sostener, por si misma, una concepción públicamente comprometida de la participación política. Piensan que para ello se hace 
necesario lograr conectar coherentemente la defensa de los derechos liberales con la persecución colectiva de fines y bienes comunes. Los dos modelos teóricos que vamos a ver brevemente aquí coinciden en subrayar la imposibilidad de activar mediante normas jurídicas la participación política de los ciudadanos. Se trata, en ambos casos, de anclar el status legal de la pertenencia a un Estado en un trasfondo sociocultural donde los individuos puedan encontrar los motivos e intenciones que les orienten hacia el bien común. En el modelo comunitarista de Taylor, el status legal del ciudadano representa la expresión formal de una identificación nacional o cultural. Los individuos participan en una comunidad cultural cuando forman y revisan sus motivos, intenciones y ambiciones en el contexto de una cultura, una lengua y una historia comunes. En el modelo democrático de Habermas, por el contrario, este anclaje cultural de la participación política no necesita en modo alguno apoyarse en características etnoculturales o históricas concretas, sino que basta con la socialización de todos los ciudadanos en una cultura constitucional posnacional basada en principios universalistas de justicia y democracia.

Creo que la tesis central de ambos modelos —que denominaré «la tesis de la pertenencia cultural»— es correcta, pero no creo que tenga las consecuencias críticas contra el liberalismo que estos autores pretenden deducir. Para Taylor, la tesis de la pertenencia cultural supone la superación de la neutralidad liberal en favor de una «política del bien común» en la que las exigencias legítimas de los individuos pierden la supremacía frente a los valores compartidos que definen la comunidad. En el liberalismo democrático de Habermas, por su parte, la tesis de la pertenencia cultural no implica una conexión conceptual entre la participación política y una identidad cultural basada en la procedencia u origen étnico, lingüístico y cul- tural, común a todos los ciudadanos, lo que permite enraizar la ciudadanía democrática en un contexto histórico-político culturalmente neutral. Para Habermas, «la sustancia ética de una integración política que mantiene unidos a todos los ciudadanos de la nación, debe permanecer «neutral» con respecto a las diferencias entre las comunidades ético-culturales existentes dentro de la nación» ${ }^{2}$.

En mi opinión, el abandono de la concepción comunitarista de la cultura nacional no permite trazar una línea divisoria tan estricta como quiere Habermas entre la política (o la cultura política) y los rasgos propiamente etnoculturales o históricos (como la lengua). La idea que defenderé en este artículo es que Habermas comete el mismo error que Taylor. Ambos suponen que la identidad cívica encargada de mantener una participación política activa ha de basarse en una cultura común compartida por todos los miembros de la asociación política. Creo que esto es falso, y que una misma identidad cívica puede estar integrada por distintas culturas nacionales sin que esto suponga compartir una misma cultura política independiente de todas ellas. No se puede usar el nombre de «cultura política» para designar lo que propiamente es una concepción política normativa - los principios de justicia del liberalismo democrático-cuya función no consiste en definir un determinado bien o fin común, sino en establecer los límites de cualquier persecución colectiva de fines comunes.

Esto no quiere decir que el liberalismo no esté comprometido con ninguna concepción del bien. La prioridad moral de los principios liberales no presupone que podamos deducirlos sin contar con lo que sabemos sobre los intereses y necesidades humanas. Antes al contrario, su fuerza normativa se basa en una cierta idea acerca de nuestros intereses esenciales y de lo que los promueve. Pero identificar esta idea con algún tipo de carácter o forma de vida 
de propiedades exclusivamente políticas significa, en la práctica, reducir indebidamente su grado de abstracción y neutralidad, sin tener, como contrapartida, una noción menos polémica o más consensuada. La concepción de la persona que acompaña a los principios políticos - rectores de las decisiones del Estado- no puede tener en cuenta otras propiedades del ser humano que aquellas que son relevantes para la justificación política. La concepción liberal de la persona supone que estos rasgos relevantes no son la raza, ni el color, ni el origen lingüístico o cultural, ni el sexo, ni la religión, sino aquellas potencialidades - como la capacidad para gobernar nuestra conducta y revisar nuestros fines-cuya realización resulta imprescindible para llevar a cabo cualquier clase de vida buena. Como es evidente, una concepción así de formal no puede suministrar una identificación compartida, ni mucho menos una identificación cívica capaz de unificar las distintas identidades nacionales de un Estado multicultural. A la inversa, es más fácil pensar que pondrá en peligro cualquier unidad social, puesto que deja abierta la valoración de las diferentes formas en que puede realizarse una vida buena. El distanciamiento valorativo que pide el liberalismo a los principios políticos no produce, como piensan los comunitaristas, sujetos desvinculados y empobrecidos, sino más bien un problema endémico de inestabilidad y disenso. El liberalismo concibe a los seres humanos como sujetos morales, capaces de apropiarse o de rechazar autónomamente cualquiera de las convicciones y creencias que su cultura les pueda proporcionar. Es más, cree que ésta es la única forma de aprender a llevar una buena vida. Pero un sujeto autónomo así entendido trasciende cualquier moralidad convencional. Como ha señalado Javier Muguerza, «aunque, en un cierto sentido, la moral como contenido - que halla expresión en códigos morales, ideologías y formas morales de vida- sea siempre «convencional» en términos de Kohlberg, su apropiación autónoma o su autónomo rechazo, por parte de un sujeto moral que cree contar con buenas razones para decidir una cosa $u$ otra instala a éste en la postconvencionalidad» ${ }^{3}$. Por este motivo, la socialización de los individuos en un Estado liberal no puede sino poner en aprietos la deseada identificación cívica de todos ellos en torno a una cultura común.

Desde un punto de vista histórico, la importancia de una cultura común en el florecimiento de una ciudadanía activa y políticamente comprometida resulta innegable. En el proceso de modernización por el que, desde fines del siglo XVIII, surgen los actuales Estados nacionales, la difusión de una cultura común no sólo sirvió para desarrollar el sistema económico capitalista, sino que permitió el nivel de solidaridad y fraternidad necesario para la democratización de los Estados — si bien a costa de la represión de las minorías nacionales. La identidad nacional, concebida desde la Revolución francesa como la apropiación consciente de una lengua y una tradición compartidas, hizo posible la identificación ciudadana, es decir, la conciencia de pertenecer a una comunidad autogobernada que exigía de sus miembros un alto grado de compromiso personal e incluso de sacrificio de sí mismo. El artículo cuarto de la Constitución revolucionaria, como nos recuerda Habermas, concedía a todo extranjero adulto que residiese durante un año en Francia, no solamente la nacionalidad francesa, sino también los derechos de ciudadanía activa. La pertenencia nacional, por tanto, no se basaba en la raza o en los ancestros, sino que estaba definida en términos de integración en una comunidad cultural. La participación política, por su parte, no era más que el reverso de esta identidad nacional.

De acuerdo con esta concepción republicana de comunidad autogobernada, Taylor afirma que no es posible la participación activa sin que los ciudadanos se 
identifiquen con una cultura común en la que se defina una forma de vida concreta, es decir, una determinada comprensión de la vida buena. La falta de participación política se debe, en opinión de Taylor, a que en las sociedades liberales modernas el gobierno debe permanecer neutral en las cuestiones relativas al bien, dejando que los individuos elijan sus fines libremente, es decir, con independencia de los fines compartidos que caracterizan la vida comunitaria. Como consecuencia de la neutralidad liberal, la política ha dejado de significar una persecución pública de fines compartidos, y pasa a ser un mero instrumento al servicio de los fines privados de los individuos. Este estado de cosas no sólo resulta para Taylor poco edificador, sino que es, según él, autodestructivo a largo plazo. La defensa de las libertades individuales en que se basa cualquier régimen liberal no se puede sostener sin promover al mismo tiempo una cultura de la libertad que contenga las prácticas e instituciones necesarias para el ejercicio efectivo de esas libertades. Sin embargo, afirma Taylor, una comunidad política gobernada por el principio de la neutralidad liberal es incapaz de mantener una cultura de este tipo, pues al instrumentalizar el bien común impide que los ciudadanos se identifiquen con cualquier clase de fin compartido. No hay participación política, concluye Taylor, cuando no hay ninguna cultura común más allá de la cultura política de los derechos individuales ${ }^{4}$.

Pero, ¿por qué cree Taylor que habrá mayor participación ciudadana en una política de fines compartidos? Defender la neutralidad política no significa, después de todo, rechazar cualquier tipo de bien común. Si en este punto hacemos caso a Aristóteles, no debemos entender el bien común únicamente como «el bien de todos», sino también en el sentido de «el bien de cada uno». Un Estado liberal promueve, en este segundo sentido, el bien común, dado que sus acciones políticas persiguen la promoción de los intereses de cada uno de los miembros de la comunidad. De ahí que a menudo se considere el bien común de un Estado liberal como el resultado de un proceso de combinación de preferencias, en el que todas ellas son tratadas igualmente - siempre que sean consistentes con los principios de justicia. No pretendo hacer aquí, por supuesto, una defensa de Aristóteles como padre del liberalismo, pero sí aprovechar su distinción anti-platónica para descargar a la neutralidad política de la acusación de impedir la identificación de los ciudadanos con un singular «bien de todos». La idea liberal de un trato neutral puede hacer más difícil esa identificación, pero no la impide. El único propósito de la neutralidad liberal es asegurar al individuo la capacidad de vetar cualquier decisión colectiva que viole su derecho a recibir del gobierno un trato neutral igual. Cada persona debe poder, según esto, formar y revisar por sí misma su propia concepción del bien, siempre que respete la capacidad de los demás para hacer otro tanto, y perseguir los fines que ella cree valiosos aunque no coincidan con los que la mayoría reconoce y aprueba como «el bien de todos». De esto no se sigue, sin embargo, que las decisiones colectivas se tengan que tomar por burócratas o por poderes centralizados. Como señaló Isaiah Berlin, el deseo de un área individual de libre acción no tiene una conexión necesaria con el deseo de participar en el proceso por el que mi vida va a ser controlada ${ }^{5}$. ¿Por qué entonces piensa Taylor que una concreta forma de vida comunitaria atraerá más la lealtad de los ciudadanos hacia el Estado que esa combinación equitativa de preferencias individuales que conlleva la neutralidad política liberal? En mi opinión, Taylor idealiza incorrectamente la política de los fines compartidos. Es cierto que una política así recaba mayor identificación de los ciudadanos con el bien común, pero a costa de marginar a las minorías en la definición 
misma de ese bien común. Como apuntábamos al principio, los grandes Estados nacionales se formaron y democratizaron en torno a una idea de identidad nacional que bien podemos considerar como una forma de vida concreta. Según Ortega y Gasset, la forma de vida nacional era, durante el siglo XIX, «un modo integral de ser hombre» ${ }^{6}$, de tal manera que pertenecer a una cultura nacional quería decir ser íntegramente hombre al modo que dictaba esa cultura, pues afectaba e impregnaba todas las dimensiones de lo humano. Sin embargo, esta forma de recabar la participación ciudadana se hizo siempre impidiendo que determinados grupos nacionales minoritarios pudieran participar en la definición misma de la forma de vida nacional supuestamente compartida. Y no sólo ellos. Si el grupo de las mujeres, el de los ateos o el de los no propietarios hubieran tenido la oportunidad de participar en la cultura común del país, no habrían elegido, a buen seguro, el mismo tipo de fines compartidos que sirvieron para la identificación nacional. No parece entonces que sea suficiente, para aumentar el nivel de compromiso político, incluir a los grupos tradicionalmente marginados en la persecución de unos fines compartidos que no tienen nada que ver con sus propios intereses.

¿Será suficiente, entonces, para aumentar el compromiso político de la ciudadanía, con sustituir esos fines compartidos, racial y culturalmente sesgados, por una cultura política común que contenga únicamente los principios democráticos y de justicia reconocidos en la constitución? Habermas piensa que sí. Según su modelo deliberativo, la participación política no necesita enraizarse en una cultura distinta de la que proporcionan los procedimientos para la formación democrática de la voluntad común. La falta de participación política activa proviene, según Habermas, no del abandono de la política de los fines compartidos, sino de una integración social dominada por la lógica sistémica de la economía capitalista y del aparato burocrático del Estado. Estos sistemas tienden a obedecer solamente a sus propios imperativos de dinero y de poder, y hacen añicos el modelo de una comunidad que se determina a sí misma a través de la práctica política común de los ciudadanos. En estas condiciones, los derechos liberales y los derechos a recibir prestaciones sociales se otorgan en términos paternalistas, pues resultan funcionales para la institucionalización de los sistemas económico y administrativo. Como consecuencia, Habermas caracteriza la orientación predominante de los ciudadanos frente al gobierno en términos de «alto output-bajo input», es decir, por una renuncia privatista a la parte activa del papel de ciudadano, que queda de este modo reducido a la categoría de un «cliente» pasivo del Estado social, cuyas únicas contribuciones al bien común se limitan al voto y a los impuestos. Frente a esta situación, la sugerencia comunitarista de reavivar la participación política mediante la persecución pública de fines compartidos le parece a Habermas demasiado concreta y simple. Las condiciones modernas, según él, no permiten a los ciudadanos otra extensión de sus derechos de participación política que por vía de integrarse en, y ejercer influencia sobre, la circulación informal de una opinión pública discursivamente formada. Sin embargo, para Habermas, esto sería suficiente con tal de que el Estado permaneciera atento a las orientaciones de esa opinión pública en la formación institucionalizada de la voluntad política. Con un sistema jurídico abierto a la opinión pública, dice Habermas, los ciudadanos se verán a sí mismos, al mismo tiempo, destinatarios y autores de las leyes que los gobiernan. En el modelo de política deliberativa que defiende Habermas, la actualización democrática de los derechos a través de la opinión pública permite que el sistema jurídico deje de ser únicamente un medio para el control buro- 
crático racionalizado de la sociedad, y se reconduzca según los intereses reales de sus ciudadanos ${ }^{7}$.

En este modelo de política deliberativa, por tanto, el núcleo de la participación política reside en la inclusión del individuo en una «esfera pública con estructuras abiertas de comunicación» que permita y promueva discusiones sobre cuál debe ser la concepción del bien compartida y la forma de vida que ha de unir a todos en una identidad común. En tales discusiones, todos los participantes tienen igual derecho a manifestar la forma en que ellos quieren considerarse como ciudadanos de una república histórica concreta, como habitantes de una determinada región o como miembros de un grupo cultural diferenciado. Pero si Habermas rechaza la «politización» de los fines compartidos por ser un modelo demasiado simple para las condiciones modernas de colonización sistémica, ¿por que defiende la «politización» de las deliberaciones sobre fines compartidos cuando reconoce la poca propensión de los sistemas a obedecer otra lógica que no sea la suya? ¿No resulta descabellado depositar nuestras esperanzas de ciudadanía activa en una supuesta porosidad del sistema legal que contradice la reconocida tendencia de los sistemas a cerrarse frente a sus entornos?

Habermas piensa que, sin la deliberación política, la gente tiende a aceptar las prácticas existentes como dadas y a perpetuar sin discusión las falsas necesidades y la falsa conciencia que acompaña a los fines y prácticas tradicionales. ¿Pero por qué otorgar a todos los ciudadanos el mismo derecho de participación política en lugar de diferenciar los derechos según el grupo cultural al que pertenezca cada ciudadano? Si diferenciamos los derechos según el grupo cultural estaremos dando a los individuos los recursos específicos para que puedan definir y reformar por su cuenta los fines que consideran valiosos y las prácticas que los promueven. Por el contrario, al elegir un modelo en el que los fines compartidos se deben discutir por toda la ciudadanía democrática, Habermas parece suponer que lo que no es objeto de discusión política está expuesto a una voluntad individual incapaz de juicio racional $^{8}$.

Por otra parte, no creo que sea posible fomentar la participación política y la lealtad al Estado integrando a todos los ciudadanos en una cultura política democrática absolutamente exenta de elementos étnicos y culturales. Habermas distingue entre la integración ética, basada en la pertenencia a una cultura determinada, y la integración política, que debería basarse exclusivamente en la aceptación de los principios políticos y los derechos democráticos. Habermas reconoce que la cultura política común contiene una interpretación específica de los principios constitucionales desde la perspectiva de la experiencia histórica de la nación, pero añade que esta sustancia ética de la cultura política no puede restar valor a la neutralidad del sistema legal en favor de las comunidades que están éticamente integradas a nivel subpolítico. El Estado, dice Habermas, debe ser neutral con respecto a los grupos étnicos y nacionales que componen el país. Pero parece evidente que éste es un imperativo que sólo puede cumplir el Estado a costa de transferir o delegar algunas de las más importantes decisiones políticas que debe tomar un gobierno.

En efecto, ningún gobierno puede evitar decidir qué lengua se utilizará en la enseñanza pública o en la provisión de los servicios estatales, cuáles serán las festividades públicas o las fronteras internas, o cómo será el diseño de la división de poderes entre los gobiernos centrales y locales. En todos estos casos, como ha señalado Will Kymlicka, la decisión estatal implicará conferir un apoyo o, al menos, una consideración especial, a una cultura concreta $^{9}$. 
Habermas ve la concesión de un status de ciudadanía democrática común, exenta de cualquier rasgo propiamente cultural, como la forma propiamente liberal de integración social, pues cree que entre el Estado legal y la cultura no existe una conexión conceptual, sino una mera relación funcional y empírica. En Europa, afirma Habermas, se debería esperar de los inmigrantes únicamente la disponibilidad a introducirse en la cultura política de su nuevo país, pero sin necesidad de tener que abandonar por ello la forma de vida cultural de la que provienen. Sin embargo, esto no se corresponde con las expectativas reales de los inmigrantes. Ellos no sólo desean disfrutar del mismo status legal de los nacionales; también esperan participar en las instituciones públicas —incluida la lengua - de la cultura dominante, pues saben que sin este tipo de participación no les quedan más salidas que la marginación social y el desempleo. A pesar de que una parte de estos grupos afirman cada vez más su derecho a expresar su particularidad étnica, lo cierto es que desean hacerlo dentro de las instituciones públicas de la sociedad dominante. Al rechazar la asimilación como forma de integración, los grupos inmigrantes no pretenden crear una sociedad paralela, como sucede de forma característica con las minorías nacionales, sino encontrar un modo de integración cultural que respete lo más posible su herencia étnica.

La conexión histórica y funcional entre la cultura y el Estado quizá no demuestre, como afirma Habermas, una conexión conceptual, pero sí creo que nos permite calificar de meramente conceptual una distinción demasiado estricta entre ambos. No puede haber una cultura política puramente ideológica, completamente vacía de caracteres etnoculturales o históricos como la lengua. Si Habermas reconoce que la cultura política de un país es la interpretación de los principios constitucionales a la luz de la experiencia compartida de esa nación, no puede al mismo tiempo hablar, sin contradecirse, de una cultura política sin una lengua y una historia compartidas.

El caso de algunos Estados multinacionales, como los Estados Unidos y Suiza, representan, según Habermas, ejemplos de culturas meramente políticas. Pero esto no es cierto. La cultura política común de los Estados Unidos sí tiene rasgos propiamente culturales, centrados en su lengua y en su historia colectiva. Como explica Kymlicka, el énfasis en los principios políticos ha configurado, desde los tiempos de la Revolución, el componente cultural de la identidad nacional estadounidense, pero sin sustituirlo por una mera ideología. «Los inmigrantes a los Estados Unidos no sólo deben comprometerse a aceptar los principios democráticos, sino que también deben aprender la lengua y la historia de su nueva sociedad» ${ }^{10}$. Un derecho liberal de inmigración, por tanto, no se caracteriza por su asepsia cultural, sino por garantizar el ingreso en la cultura común a cualquier persona que, con independencia de su raza o de su origen, esté dispuesto a aprender la lengua y la historia de la sociedad y a participar en sus instituciones sociales y políticas.

El caso de Suiza es diferente, pues se aproxima más a un verdadero Estado multinacional. Para Habermas, la única manera de desarrollar una identidad cívica compartida en este tipo de Estados consiste en otorgar un status de ciudadanía democrática común e indiferenciado a todos los miembros de la comunidad política. Esto permitiría, en su opinión, una transformación democrática de los derechos capaz de garantizar a los diferentes grupos étnicos del país y a sus formas de vida culturales unos derechos iguales de coexistencia. Pero para que se dé esta protección legal de las culturas no es necesario, según Habermas, defender unos derechos colectivos que contradicen el diseño individualista de la teoría liberal de los derechos. 
Es suficiente con la inclusión de los grupos nacionales minoritarios en una esfera pública política donde puedan discutir en igualdad de condiciones con los otros grupos nacionales sobre los fines compartidos, otorgándoles en todo caso a dichas minorías un grado superior de representación en aquellos ámbitos de la política que resulten más sensibles para su identidad cultural. Lo que en ningún caso permite, en opinión de Habermas, una teoría liberal de los derechos es la diferenciación del status legal en función del grupo cultural de pertenencia, pues el marco de la Constitución de un Estado democrático de derecho permite la coexistencia en régimen de plena igualdad a múltiples formas de vida, siempre que éstas se solapen en una cultura política común no identificada con ninguna de ellas. Al igual que el último Rawls, Habermas afirma que lo que une a las sociedades pluralistas modernas es una concepción compartida de la justicia, que él identifica con los principios constitucionales.

Sin embargo, no está claro que dicha cultura política compartida, por sí misma, sea una razón para que dos o más grupos nacionales permanezcan unidos en un país, y, en ningún caso, para que dos países separados decidan unirse. Nunca han tenido las naciones en el mundo occidental una cultura política tan semejante como en nuestros días, sin que esto haya producido ningún efecto significativo en su deseo por conservar su independencia nacional - aparte de las necesarias concesiones impuestas por la economía «global». Como reconoce el propio Habermas en el caso de la unificación europea, los procesos democráticos sólo funcionan de hecho dentro de los grupos nacionales. ¿Por qué no habría entonces de ocurrir otro tanto en los Estados que contienen diversos grupos nacionales con un fuerte sentimiento de identidad diferenciada? ¿Por qué supone Habermas que un consenso meramente formal en torno a los principios democrá- ticos puede sustituir a la identidad nacional como fuente de la identidad cívica y, por ende, de la participación política?

En Suiza, como en la mayoría de los Estados multinacionales $-\mathrm{y}$ como es de suponer que ocurra en una hipotética federación europea-, los distintos grupos nacionales sienten lealtad hacia el Estado en su totalidad, no tanto porque éste represente una cultura política común, sino porque reconoce y promueve su existencia como naciones diferentes, con culturas políticas diferenciadas. En las sociedades donde se da este tipo de pluralidad cultural, la «ciudadanía común» implica, en la práctica, apoyar la cultura de la nación mayoritaria.

Habermas teme que si no separamos el Estado de la cultura, la sociedad dominante se apropiará del aparato coercitivo estatal para recortar o terminar con las formas de vida de las minorías culturales. Creo, sin embargo, que es precisamente la distinción entre Estado y cultura la que permite a la sociedad dominante actuar desde el gobierno como si no existiera ninguna otra cultura societal distinta en el país. Un Estado multinacional que concede un mismo status de derechos a todos los ciudadanos, con independencia de su pertenencia cultural, puede parecer «neutral» entre los diversos grupos nacionales, pero de hecho favorece a una cultura determinada, que generalmente es la mayoritaria, cuando decide cuál será la lengua oficial del país o el curriculum obligatorio en las escuelas públicas. La implicación del Estado y la cultura es inevitable, por lo que el argumento de imparcialidad que utiliza Habermas para defender el mismo derecho a coexistir de todos los grupos nacionales no puede hacerse efectivo sin reconocer a los grupos minoritarios los derechos de autogobierno necesarios para protegerse de las decisiones ético-políticas de la mayoría.

Según el modelo de Habermas, la actualización democrática de los derechos per- 
mite que el sistema jurídico quede penetrado por la ética de la comunidad cultural, procurando así el reconocimiento legal de la forma (o formas) de vida que existen (o coexisten) dentro del país. Lo que no tiene en cuenta Habermas es que, si esa comunidad es multinacional, entonces la formación democrática de los derechos tendrá que desembocar necesariamente en el reconocimiento de distintos status legales por razón del grupo cultural para las diversas minorías nacionales. Este resultado parece insoslayable si nos atenemos al hecho de que las minorías nacionales no quieren participar en una política común, sino que — con objeto de fomentar la igualdad entre la mayoría y la minoríase les reconozca como sociedades políticas diferenciadas, con derechos lingüísticos y autonomía territorial.

Para Habermas, como para muchos liberales, los derechos de autogobierno representan una amenaza para la función integradora de la ciudadanía, pues constituyen el caso más claro y completo de ciudadanía diferenciada en función de la pertenencia cultural. Las reivindicaciones de autogobierno no exigen un aumento en los derechos de representación, como ocurre en el caso de aquellos grupos que están en situación de desventaja dentro de la comunidad política, ni tampoco un mero reconocimiento de la diversidad cultural existente en el país, como sucede en las reivindicaciones de los inmigrantes. Lo que reivindican los grupos nacionales es que hay más de una comunidad política, y que el Estado en su conjunto no puede hacer prevalecer su autoridad sobre las comunidades nacionales que lo constituyen. En mi opinión, un derecho liberal de autogobierno debería asegurar que todos los grupos nacionales tengan la posibilidad de mantenerse como cultura distinta - lo cual significa, en términos de Berlin, ser poseedores de «libertad negativa», o, en palabras de Kymlicka, de «protecciones externas»-

Naturalmente, la concesión de este derecho pone en peligro la unidad de la comunidad política. ¿Deberíamos entonces, en beneficio de la unidad social, defender el mismo status de derechos para todos los ciudadanos? No lo creo. Como señala Kymlicka, la ciudadanía común en los Estados multinacionales transforma los grupos potencialmente autogobernados en mayorías y minorías numéricas, lo que no sólo no ayuda a conjurar el peligro de fragmentación, sino que más bien contribuye a crearlo. Por contra, pienso que es posible generar un fuerte sentimiento de solidaridad y compromiso mutuo dentro de una comunidad política compuesta por grupos nacionales autogobernados, siempre que esa comunidad se presente como el contexto en el se nutren las identidades separadas que la integran. Cualquier sociedad tiende a sentirse como un todo, «más sentirse como un todo», dijo Ortega, «no excluye que, a la vez, sienta ese su todo como parte de otro más amplio» ${ }^{11}$.
${ }^{1}$ En esta primera acepción del concepto, me ajusto a la definición que ofrece Quentin Skinner de libertad política: «el ámbito de libertad de acción de que disponen los agentes individuales dentro de los límites impuestos sobre ellos por su pertenencia a una sociedad política» (Q. Skinner, «The idea of negative liberty», en R. Rorty,
J. B. Schneewind y Q. Skinner, Phylosophy in History, Cambridge, Cambridge University Press, 1998, p. 194)

2 J. Habermas, «Struggles for Recognition in the Democratic Constitutional State», en A. Gutmann (ed.), Multiculturalism, Princeton, Princeton University Press, 1994, p. 137. 
${ }^{3}$ J. Muguerza, «De la conciencia al discurso: ¿un viaje de ida y vuelta?», en J. A. Gimbernat (ed.), $L a$ filosofía moral y política de Jürgen Habermas, Madrid, Biblioteca Nueva, 1997, p. 81.

${ }_{4}$ Estas ideas están recogidas en varios artículos de Taylor; entre ellos, cabe mencionar los dedicados a la filosofía política en sus Philosophical Papers, vol. 2 , Cambridge, Cambridge University Press, 1985; «Cross-Purposes: The Liberal-Communitarian Debate», incluido en sus Philosophical Arguments, Cambridge, MA, Harvard University Press, 1995, pp. 181-204, $\mathrm{y}$ «The Politics of Recognition», en A. Gutmann (ed.), Multiculturalism, op. cit., pp. 25-75.

${ }^{5}$ En un pasaje de su célebre artículo «Two concepts of liberty», Berlin afirma: «El autogobierno puede ofrecer, frente a otros regímenes, una mejor garantía para la preservación de las libertades civiles, y como tal ha sido defendido por los libertarios. Sin embargo, no existe una conexión necesaria entre la libertad individual y la regla democrática. La respuesta a la pregunta «iQuién me gobierna?» es lógicamente distinta de la pregunta «ihasta dónde interfiere el gobierno en mis asuntos?». En esta diferencia consiste el enorme contraste entre los dos conceptos de libertad negativa y positiva», Four Essays on Liberty, Londres, Oxford University Press, 1969, p. 130.

6 J. Ortega y Gasset, Europa y la idea de Nación, Madrid, Alianza, 1985, p. 73.

7 Habermas expone estas ideas, fundamentalmente, en los artículos «Ciudadanía e identidad nacional», Facticidad y validez, Madrid, Trotta, 2000; y «Struggles for Recognition...», Multiculturalism, op. cit.

${ }_{8}$ Javier Muguerza ha lamentado en varias ocasiones la descalificación que Habermas prodiga a «los fueros de la privacidad». Véase, por ejemplo, «Entre el liberalismo y el libertarismo (Reflexiones desde la ética)», en J. Muguerza, Desde la perplejidad, México, Madrid, Buenos Aires, Fondo de Cultura Económica, 1990, as como el ya citado «De la conciencia al discurso...».

9 W. Kymlicka, Ciudadanía multicultural, Barcelona, Paidós, 1996, pp. 80 y ss.

${ }^{10}$ W. Kymlicka, Ciudadanía multicultural, op. cit., pp. $42-43$

11 J. Ortega y Gasset, Europa y la idea de Nación, op. cit., p. 83 . 